DOI: $10.5455 / 2320-1770 . i j \operatorname{cog} 20130924$

Research Article

\title{
A retrospective study of teenage pregnancy in a tertiary care hospital
}

\author{
Samar Rudra ${ }^{1}$, Himadri Bal ${ }^{2}$, Swati Singh $^{1}$ \\ ${ }^{1}$ Department of Obstetrics and Gynecology, MMIMSR, Mullana, Ambala, India \\ ${ }^{2}$ Department of Obstetrics and Gynecology, Padmasree Dr DY Patil Medical College Hospital \& Research, Pune, India
}

Received: 23 June 2013

Accepted: 11 July 2013

*Correspondence:

Dr. Swati Singh,

E-mail: swatisingh0011@gmail.com

(C) 2013 Rudra S et al. This is an open-access article distributed under the terms of the Creative Commons Attribution Non-Commercial License, which permits unrestricted non-commercial use, distribution, and reproduction in any medium, provided the original work is properly cited.

\begin{abstract}
Background: The objective of the study was to evaluate the maternal and fetal outcome of teenage pregnancy and find the effect of antenatal care on these teen mothers.

Methods: A retrospective case study was performed over a period of three years. Data was retrieved from the hospital record. All teenage mothers (aged less than 19 years) delivering in the hospital were taken as cases. Consecutive two deliveries in the age group of 20 to 30 years meeting the inclusion and exclusion criteria were taken as control group. Various aspects of pregnancy outcome was recorded and analyzed.

Results: The incidence of teenage pregnancy over the three years of study period was $4.33 \%$. The occurrence of hypertensive disorders $32(9.4 \%)$ vs $36(5.3 \%)$, p value < 0.01 ; IUGR $23(6.7 \%)$ vs $11(1.6 \%)$, p value < 0.01 ; preterm delivery $38(11.2 \%)$ vs $18(2.6 \%)$ p value < 0.01 ; and full term normal delivery $258(75.9 \%)$ vs $563(82.7 \%)$, (p value $<0.01$ in the study group and control group respectively. Low birth weight babies $140(41.2 \%)$ vs $63(9.3 \%)$, p value $<0.01$ and NICU admission $20(5.8 \%)$ vs $9(1.3 \%)$, p value < 0.01 ; were significantly higher in the study group. The comparison of various pregnancy outcomes according to the booking status of the teenage mothers finds significant improvement in most of the parameters in those who received adequate antenatal care.

Conclusion: The pregnancy outcome of teenage mothers is poorer in comparison to 20 to 30 years age group in most of the parameters. Adequate antenatal care reduces the incidence of adverse pregnancy outcome significantly in the teen mothers.
\end{abstract}

Keywords: Teenage pregnancy, Primigravidae, Adolescent

\section{INTRODUCTION}

WHO defines the period between 10-19 years of age as the adolescent period also called as teenage. Adolescence means a transitional stage of physical, psychological and physiological development, involving biological, social and mental changes. Pregnancy in this transitional stage puts them in a stressful condition. Teenage pregnancy is a common public health and social problem with adverse medical consequences worldwide.

WHO estimates that risk of death following pregnancy is twice as great for women between 15 to 19 years than those between 20 to 24 years. ${ }^{1}$ The incidence of teenage pregnancy shows marked variation, in developed and developing countries. In India, incidence of teenage pregnancy varies from $3.2 \%$ to $18.6 \%$. $^{2}$

According to the UNICEF 2011 report, the adolescent population in India is $20 \%$ of the total population i.e. almost 243 million. $27 \%$ of girls aged 15 to 19 years are married with a birth rate of 45 per 1000 girls in this age group. ${ }^{3}$ Early marriages are a long established custom in India resulting in the high incidence of teenage pregnancy. The rate is higher in the rural than in urbanized areas. Despite the law, the problems of teenage 
marriages and subsequent pregnancies are widely prevalent in India.

Developing countries have distinctly different rates of teenage pregnancy. In developed regions, such as North America and Western Europe, teenage parents tend to be unmarried and adolescent pregnancy is seen as a social issue. By contrast, teenage parents in the developing countries are often married, and their pregnancy may be welcomed by the family and society. However, early pregnancy combined with malnutrition, illiteracy and poor health care cause serious socio-medical problems. The social handicaps to the mother, loss of educational opportunity, risk of future with financial disadvantage are additional sources of concern. Recent studies indicate that good prenatal care and attention to psychosocial and economic problems of pregnancy along with intensive nutritional counseling reduce perinatal death and complication rate for pregnant teenagers. It is important to maximize the utilization of prenatal, intranatal and postnatal care services among adolescent mothers. An early booking and regular antenatal check up with proper nutritional advice can reduce the complications to a great extent.

In this study we have evaluated various outcome of teenage pregnancy and the effect of antenatal care to these mothers from the hospital records.

\section{Aims and Objectives}

1. To find out the incidence of teenage pregnancy.

2. To study maternal and fetal outcome in teenage pregnancy.

3. To compare the outcome of teenage pregnancy with that of 20 to 30 years age group.

4. To compare the outcome of booked and unbooked teenage pregnancy.

\section{METHODS}

This retrospective study was undertaken at a tertiary care urban hospital from Sept. 2009 to Aug 2012. Data was retrieved from hospital record for the study period. Pregnancy occurring by $19^{\text {th }}$ completed years of age at the time of delivery was taken as teenage pregnancy. All teenage pregnancies delivered during the study period were taken as cases. Two consecutive deliveries in the age group of 20 to 30 years meeting the inclusion and exclusion criteria were taken as control group. At least 3 antenatal visits to antenatal clinic was taken as a booked case.

Following criteria were followed:

\section{Inclusion Criteria}

1. Only singleton pregnancy was included.

2. Study group: Up to 19 years of age at the time of delivery.

3. Control group: 20-30 years.

\section{Exclusion Criteria}

1. Women more than 30 years of age

2. Pregnancy which ended in abortion.

3. Pregnancy with preexisting major medical and surgical illness which could affect the outcome.

Detailed obstetric and neonatal information was noted down in a predetermined data sheet. Maternal outcome measures included presence of anemia, pregnancy induced hypertension, preterm labour, IUGR, abruptio placentae, post-partum hemorrhage, mode of delivery, number of operative delivery. Perinatal outcome measures included birth weight, Apgar score, perinatal mortality and perinatal morbidities leading to admission to the neonatal care unit like respiratory distress syndrome, neonatal sepsis, meconium aspiration syndrome, jaundice and hypoglycemia. Data were analyzed and statistical significance tested. A p value less than 0.05 was considered statistically significant.

\section{RESULTS}

During the study period of three years, there were 8032 deliveries in the hospital, out of which the number of teenage pregnancies who delivered were 348 . Thus, giving the incidence of teenage pregnancy as $4.33 \%$. 8 cases did not meet the inclusion criteria and were excluded from the study. 340 cases included in the study group. 680 cases in the 20 to 30 years age group, selected randomly as described before were included in the control group. The youngest age of teen age mother recorded in the study was 16 years. Majority of the adolescent mothers numbering 239 were 19 years of age $(70.3 \%)$ followed by 18 years numbering $86(25.3 \%), 17$ years numbering $12(3.5 \%)$ and 3 cases $(0.9 \%)$ were 16 years of age (Table 1).

Table 1: Age distribution: teen age group.

\begin{tabular}{|lllll|} 
& 19 & 18 & 17 & 16 \\
& Years & Years & Years & Years \\
\hline Number & 239 & 86 & 12 & 03 \\
\hline Percentage & 70.3 & 25.3 & 3.5 & 0.9 \\
\hline
\end{tabular}

Table 2 shows a comparative analysis of various maternal outcomes in teenage group and control group of 20-30 yrs of age. We found that $33(9.7 \%)$ teen mothers were anemic in comparison to $40(5.9 \%)$ mothers of $20-30$ years age ( $p$ value $<0.01)$. Similarly most of the criteria evaluated by us reveal that the teenage group performed poorer than the control group. The occurrences of hypertensive disorders $32(9.4 \%)$ vs $36(5.3 \%)$ p value < 0.01 , IUGR $23(6.7 \%)$ vs $11(1.6 \%)$ p value $<0.01$, preterm delivery $38(11.2 \%)$ vs $18(2.6 \%)$, p value $<0.01$ as well as full term normal delivery $258(75.9 \%)$ vs 563 $(82.7 \%)$ p value $<0.01$; in the study group and control group respectively. We did not find any significant difference in instrumental delivery in the two groups 
$2(0.5 \%)$ vs $10(1.5 \%)$, probably because of less number of cases. $46(13.5 \%)$ patients in the study group and 98 $(14.4 \%)$ in the control group underwent caesarean delivery, and difference was not significant. Teenage group had only one case $(0.3 \%)$ of post caesarean pregnancy, whereas 20 -30 years age group had 20 cases, which is $2.9 \%$ of total cases and $20.4 \%$ of total caesarean delivery. This indicates that post caesarean pregnancy as a indication for caesarean was more than one fifth of the cases effecting the total number of caesarean in the control group. On further analysis of caesarean deliveries, we found that the study group had higher emergency caesarean rate, $32(9.4 \%)$ vs $44(6.5 \%)$; and the control group had higher elective caesarean rate $54(7.9 \%)$ vs 14 (4.1\%). There were 4 cases of breech in each group. Only one eclampsia found in this study in the 20-30 years age group. Premature rupture of membrane was significantly high in our study group in comparison to control group $11(3.2 \%)$ vs $7(1 \%)$, p value $<0.05$. There were 2 cases of antepartum hemorrhage in 20-30 years mother and no cases in teen mothers. Both group had 3 cases of postpartum hemorrhage.

As shown in table 3 low birth weight babies (less than 2.5 $\mathrm{Kg})$ were significantly higher in the study group $(41.2 \%$ vs $9.3 \%$, p value <0.01) as well as NICU admission (5.8\% vs $1.3 \%$, p value <0.01). Low Apgar score, septicaemia, hyperbilirubinaemia and prematurity were some of the most common causes for the increased NICU admission in the study group. However number of still born did not show any significant difference may be due to small numbers.

Table 3: Fetal outcome.

\begin{tabular}{|llll|}
\hline & LBW & $\begin{array}{l}\text { Still } \\
\text { born }\end{array}$ & $\begin{array}{l}\text { NICU } \\
\text { Admission }\end{array}$ \\
\hline $\begin{array}{l}\text { Adolescent } \\
\text { Group }\end{array}$ & 140(41.2\%) & $5(1.5 \%)$ & 20(5.8\%) \\
\hline $\begin{array}{l}\text { Control } \\
\text { Group }\end{array}$ & $63(9.3 \%)$ & $2(0.3 \%)$ & $9(1.3 \%)$ \\
\hline P value & $<0.01$ & NS & $<0.01$ \\
\hline
\end{tabular}

Comparison of various pregnancy outcomes according to the booking status of the teenage mothers finds significant improvement in most of the parameters in the teen mothers who received adequate antenatal care. Anemia improved from $19.1 \%$ to $7.4 \%$ (p value <0.01); hypertensive disorder, $17.6 \%$ to $7.4 \%$ (p value $<0.05$ ); IUGR, $11.8 \%$ to $5.5 \%$ (p value <0.05); preterm birth $19.1 \%$ to $9.1 \%$ ( $\mathrm{p}$ value $<0.05$ ); caesarean delivery, $23.5 \%$ to $11 \%$ (p value < 0.05 ) and NICU admission, $14.7 \%$ to $3.6 \%$ ( $\mathrm{p}$ value $<0.01$ ) as well as low birth weight babies from $61 \%$ to $36 \%$ ( $p$ value $<0.01$ ) in the unbooked to booked teenage mothers (Table 4).

Table 2: Maternal outcome of pregnancy.

\begin{tabular}{|lll|lllll|}
\hline & Anaemia & $\begin{array}{l}\text { Hypertensive } \\
\text { Disorders }\end{array}$ & IUGR & Preterm & FTNVD & $\begin{array}{l}\text { Instrumental } \\
\text { Delivery }\end{array}$ & LSCS \\
\hline $\begin{array}{l}\text { Adolescent } \\
\text { Group }\end{array}$ & $33(9.7 \%)$ & $32(9.4 \%)$ & $23(6.7 \%)$ & $38(11.2 \%)$ & $258(75.9 \%)$ & $2(0.5 \%)$ & $46(13.5 \%)$ \\
\hline $\begin{array}{l}\text { Control } \\
\text { Group }\end{array}$ & $40(5.9 \%)$ & $36(5.3 \%)$ & $11(1.6 \%)$ & $18(2.6 \%)$ & $563(82.7 \%)$ & $10(1.5 \%)$ & $98(14.4 \%)$ \\
\hline P value & $<0.01$ & $<0.05$ & $<0.01$ & $<0.01$ & $<0.01$ & NS & NS \\
\hline
\end{tabular}

Table 4: Comparison of booked and unbooked teenage pregnancy.

\begin{tabular}{|c|c|c|c|c|c|c|c|c|c|}
\hline & No. & Anaemia & $\begin{array}{l}\text { Hypert. } \\
\text { Disorder }\end{array}$ & IUGR & Preterm & FTND & LSCS & LBW & $\begin{array}{l}\text { NICU } \\
\text { Adm. }\end{array}$ \\
\hline Booked & 272 & $\begin{array}{l}20 \\
(7.4 \%)\end{array}$ & $\begin{array}{l}20 \\
(7.4 \%)\end{array}$ & $\begin{array}{l}15 \\
(5.5 \%)\end{array}$ & $\begin{array}{l}25 \\
(9.1 \%)\end{array}$ & $\begin{array}{l}218 \\
(80.1 \%)\end{array}$ & $\begin{array}{l}30 \\
(11 \%)\end{array}$ & $\begin{array}{l}98 \\
(36 \%)\end{array}$ & $\begin{array}{l}10 \\
(3.6 \%)\end{array}$ \\
\hline Unbooked & 68 & $\begin{array}{l}13 \\
(19.1 \%)\end{array}$ & $\begin{array}{l}12 \\
(17.6 \%)\end{array}$ & $\begin{array}{l}8 \\
(11.8 \%)\end{array}$ & $\begin{array}{l}13 \\
(19.1 \%)\end{array}$ & $\begin{array}{l}40 \\
(58.8 \%)\end{array}$ & $\begin{array}{l}16 \\
(23.5 \%)\end{array}$ & $\begin{array}{l}42 \\
(61 \%)\end{array}$ & $\begin{array}{l}10 \\
(14.7 \%)\end{array}$ \\
\hline $\mathrm{P}$ value & & $<0.05$ & $<0.05$ & $<0.05$ & $<0.05$ & $<0.05$ & $<0.05$ & $<0.01$ & $<0.05$ \\
\hline
\end{tabular}

\section{DISCUSSION}

Teenage pregnancy is a global problem. However there is a distinct difference between developed countries and the rest of the world in various aspects of teenage pregnancy. In western countries most of the teenage mothers are either unmarried or from socially deprived section. In contrast the teenage pregnancies in India are mostly married and it is welcome by the family and society. Recent NFHS - 3 data reveals majority of women in India marry during their teens. Among young women aged 1519 years, $16 \%$ have already begun child bearing. Median age of marriage in India is 17.2 years. ${ }^{4}$ Teenage pregnancy is a social burden in India. In the present 
study, we intended to find various pregnancy outcome of teenage pregnancy and compared it to 20-30years age group. 20-30 year age group is considered ideal age for pregnancy outcome. ${ }^{5}$

In our study, the incidence of teenage pregnancy was $4.33 \%$ (348/8032). This figure is comparable to the reported incidence of $3.2 \%$ to $18.6 \%$ in India. $^{2}$ The youngest teenage mother in our study is 16 years. Hence, the teenage group in our study fall in the category of older teenage group and all of them were married. It is possible that the unmarried teenage mothers do not come to these hospitals for reasons of secrecy.

In our study we have found that various parameters of maternal outcome like anemia, PIH, IUGR, pre term birth and operative deliveries among teen mothers were poorer in comparison to 20-30 years age group. These results are similar with other various studies. ${ }^{6,7}$

In developing countries over $50 \%$ of pregnant women suffer from iron deficiency anaemia. ${ }^{8}$ It is also prevalent among adolescent girls because the growth spurt and onset of menstruation increase iron requirements. Iron supplementation during adolescence is one of the new strategies advocated to improve iron balance in pregnancy. ${ }^{9}$ Incidence of anemia in our study is $9.7 \%$ and $5.9 \%$ in adolescent and control group respectively which is lower in comparison to findings of most of the studies because we have taken the FOGSI criteria of $10 \mathrm{gm} \%$ as cut off for leveling the patient as anaemia. ${ }^{10}$ Preterm labour in teenage pregnancy may be due to poor nutrition, anemia, PIH, incomplete maturation of teenager's reproductive organs and lack of antenatal care. Different series reported high incidence of preterm labour in teenagers. In our study, the incidence of preterm delivery is significantly high in teen mothers $(11.2 \%)$ compared to control group $(2.6 \%)$. Ovros $\mathrm{H}$ et $\mathrm{al}^{11}$ mentioned that in their study, incidence of preterm delivery was $18.6 \%$. This is comparable with our study. Most of the studies have reported an increased incidence of pre-eclampsia and gestational hypertension in adolescent pregnancies compared to the older gravidas, especially those less than 16 years. $^{12}$ Others reported a similar incidence or even lower pre-eclampsia rates among the teenagers and some have found a decrease incidence of these complications in developed countries. ${ }^{13}$ The incidence of PIH in teenage group is higher and statistically significant when compared to the control group in our study.

There are marked differences in the reported incidence of operative and instrumental deliveries by various studies. It has been stated by some studies that operative vaginal delivery and caesarean delivery in adolescent pregnant women are higher compared with pregnant adult women. ${ }^{14}$ On the contrary, several studies reported that caesarean delivery rates were lower in the adolescent group compared to control group. ${ }^{15,16}$ In accordance with these studies, our results shows that in the adolescent group caesarean delivery rate was slightly lower than that of the adult group (13.5\% vs 14.4\%) and similar observation was made for instrumental delivery $(0.5 \%$ vs $1.5 \%)$. It was interesting to note that the indication of previous caesarean for the operative delivery contributed $12 \%$ in control group vs $0.3 \%$ in adolescent group. The incidence of elective and emergency caesarean was completely different in the two groups. Elective caesarean was $4.1 \%$ in adolescent group vs $7.9 \%$ in the control group where as emergency caesarean was $9.4 \%$ vs $6.5 \%$ respectively. The increase emergency caesarean rate in the adolescent group is probably due to more intranatal complications indicating adverse pregnancy outcome in this group.

Similarly, the fetal outcomes like incidence of LBW babies, neonatal morbidity, stillbirth and NICU admission results were poorer in teenage group compared to 20-30 year group. In our study, LBW babies in teenage group and control group was $(41.2 \%$ vs $9.3 \%)$ which is statistically significant and in accordance with various other studies. ${ }^{14}$ Also, in our study low APGAR scores at birth, respiratory complications and septicaemia were associated with more babies of teenage mothers, necessitating NICU admission (5.8\%) in comparison to control mothers $(1.5 \%)$, which is statistically significant. High incidence of low birth weight babies and other adverse neonatal outcome indicate poor nutritional status coupled with demand of nutrition for her own growth affecting the fetus.

Importance of adequate prenatal care especially in adolescent pregnancy to reduce the adverse outcome is well known. On further analysis of the pregnancy outcome data's of the teenage group with regards to their booking status in their antenatal period, we found that all the parameters of pregnancy outcome were better in those who received antenatal care in their pregnancy. As in our study, older teenagers (16-19 years) are the majority of teenage mothers in India and most of them are married. They often have adequate social and psychological support from the family. If they receive proper antenatal care, outcome of pregnancy improves to a comparable level to the adult age group. A benefit of prenatal care in the pregnancy is a well established fact. The effects of prenatal care specially to the teen mothers is reemphasised in our study as in some other studes. ${ }^{17,18}$

\section{CONCLUSION}

The pregnancy outcome of teenage mothers is poorer in comparison to 20 to 30 years age group in most of the parameters. Improving the general health and nutrition of the girl child, increasing the age of marriage and subsequent childbearing along with adequate antenatal care reduces the incidence of adverse pregnancy outcome. Therefore, we conclude that our strategy to tackle the problem of teenage pregnancy should be directed to reach out to this vulnerable group with our health care system. The Government initiative like Adolescent Reproductive and Sexual Health (ARSH) 
clinics should be used effectively for utilization of their services with a view to encompass all aspects of adolescent problems including prevention as well as prenatal care of adolescent pregnancy.

\section{Funding: None}

Conflict of interest: None declared

Ethical approval: Not required

\section{REFRENCES}

1. Mawer C. Preventing teenage pregnancy, supporting teenage mothers BMJ1999; 318:1713-14.

2. Sen S. Status of Adolescents: glimpses from states of Indian. Health for the millions 2004;29:31-2.

3. The state of world's children 2011, Adolescent: An age of opportunity, UNICEF, Feb 2011, page 130.

4. International Institute of population sciences (IIPS) and macro international. 2007. National Family health survey (NFHS-3) 2005-06;15-19.

5. Iqbal F, Azad S, Tayyab R. Obstetrical and fetal outcome in teenage primigravida. Annals King Edward Med Coll 2004; 14: 470-2.

6. Verma V, Das KB. Teenage primigravidae: A comparative study. Indian J Pub Health. 1997;412:52-55.

7. Kore ST, Rao S, Bhagwat A, Ishwar G, Vaidyanathan V, Kulkarni VA, et al. The challenge of adolescent pregnancies- experiences at a tertiary referral centre. Indian Medical Gazette 2004;502-4.

8. Saxena P, Salhan S, Chattopadhyay B, Kohli M, Nandan D, Adhish SV. Obstetric and perinatal outcome of teenage and older primigravidas- a retrospective analysis. Health and Population: Perspectives and Issues 2010:33(1):16-22.

9. Lynch SR. The potential impact of iron supplementation during adolescence on iron status in pregnancy. J Nutr 2000;130(2s Suppl):448s-451s.
10. Pandit S, Deshmukh PB, Khan RJ. Clinical signs and symptoms of IDA. Fogsi Focus: Iron deficiency anaemia;2008:18-20.

11. Orvos H, Nyirati I, Hajdu J, Pal A, Nyari T, Kovaca L. Is adolescent pregnancy associated with adverse perinatal outcome? J Perinat Med 1999;27:199-203.

12. Brindis CD. A public health success: understanding policy changes related to teen sexual activity and pregnancy. Annual Review of public health 2006; 27;277-95

13. Watcharaseranee N, Pinchantra P, Piyaman S. The incidence and complications of teenage pregnancy in Chonburi Hospital. J Med Assoc Thai 2006;89:S118-S123.

14. Scholl TO, Hediger ML, Belsky DH. Prenatal care and maternal health during adolescent pregnancy: a review and meta-analysis. $\mathrm{J}$ Adolesc Health 1994;15:444-56.

15. Pavlova - Greenfield T, Sutija VG, Gudovalli M. Adolescent pregnancy: positive perinatal outcome at a community hospital. J Perinat Med 2000; 28: 4436.

16. Lubarsky SL, Schiff E, Friedman SA, Mercer BM, Sibai BM. Obstetric characteristics among nulliparas under age 15 . Obstet Gynecol 1994;84:365-8.

17. Naqvi MM, Naseem A. Maternal and Fetal Risks Associated with Teenage and Adult Pregnancy. JRMC;2010:14(1):40-2.

18. Mutihir JT, Maduka WE. Comparison of Pregnancy Outcome Between Teenage and Older Primigravidae in Jos University Teaching Hospital, Jos, North-Central Nigeria. Annals of African Medicine 2006;5:101-6.

DOI: 10.5455/2320-1770.ijrcog20130924

Cite this article as: Rudra S, Bal H, Singh S. A retrospective study of teenage pregnancy in a tertiary care hospital. Int J Reprod Contracept Obstet Gynecol 2013;2:383-7. 